\title{
Production rate optimisation - avoiding the temptation of tonnage
}

\author{
P. McCarthy AMC Consultants Pty Ltd, Australia
}

\begin{abstract}
A feasibility study is a prediction of future events. Modern computing techniques have allowed estimates to be made with increasing precision but may not have improved their accuracy. A mine (including mill and infrastructure) is a complex dynamic system, so that any description of a future mine built up from estimates of its component parts must be tempered by an appreciation of how the system performs as a whole. While software models are proceeding toward the goal of whole-system simulation, the models must be calibrated against real-world performance. This can only be achieved by benchmarking modelled performances and costs against comparable real-world examples. With the current level of sophistication of modelling, benchmark data must take precedence over model outputs and in that respect we may be no more advanced in predicting whole-of-mine performance than we were in the pre-computer era.
\end{abstract}

One key optimisation parameter is the mine's production rate. If a scheduling package suggests that a particular production rate can be achieved then this must be verified and moderated by benchmarking, with particular regard to the relationship between production rate and head grade. The assumption that "economies of scale" will result from increasing throughput rates needs to be balanced by an awareness of the adverse effects of increasing the rate beyond a level that is supportable by the resource.

At low to moderate production rates the forecast ore reserve grade and mining recovery may be achieved comfortably. However, as the challenge of meeting production targets increases, mining becomes less selective, more waste finds its way into the ore steam and ore that requires careful extraction may be abandoned. Without changing the intended cutoff grade, the actual head grade will fall as the mining rate increases. This effect is known to people at operations but is not generally recognised in current ore reserve estimation methodology or in mine optimisation studies.

The dependency of head grade on mining rate can be quantified and used to establish the economically optimum mining and processing rate for a new project. A practical analysis is set out based on real-world examples.

\section{Introduction}

The production rate for a new mine is selected by balancing the potential return on investment against the required capital and the risk of failure. The ability of markets to absorb the output is rarely an issue. Hoover (1909) said "The lower the production rate, the lower the required investment, the longer the income stream and the lower the risk to the investor". While this was well before the advent of Discounted Cash Flow (DCF) analysis, the point made remains a good one.

The risk arising from increasing the designed throughput takes two forms; first that the mine will be unable to deliver the material to the mill, and second that although the tonnage target is met, the material will be of inadequate quality due to dilution or contamination. A study reported by Tatman (2001) compared designed production rate with the average sustained production rate from 60 steeply dipping tabular deposits. Tatman (2001) found that $35 \%$ of the mines did not achieve their planned production rate, and was able to derive an empirical formula relating the risk of failure to the geometry of the deposit and the rate of mining. Tatman (2001)'s conclusions are consistent with the author's observations for underground mines (McCarthy, 1993) that in general there is a limiting rate of mining advance (typically about 60 vertical metres per year) beyond which either the ore tonnage or head grade, or both, cannot be sustained. 
A similar rule can be developed for other forms of underground mining and, expressed as metres or benches advanced per year, for surface mining.

The physical limit to the rate at which any orebody can be mined is dictated by the possible rate of development, available face length (in a pit) or available stopes (underground), grade control turnaround, and so on. There is also an economically optimum rate, which is lower than the physical limit of mine production, beyond which the negative influences of a high rate of mining begin to outweigh the incremental cost advantages. It is also clear that mining slowly is more predictable, while attempting to mine quickly leads to greater production volatility and a less certain outcome. As more capital is invested in the larger operation, it has a higher commercial risk.

In most feasibility studies, there is an implicit attempt to maximise production within "safe" limits. This may not be the optimum strategy. In particular, the negative impact on head grade of a high mining rate is well known in operations but is ignored in the literature on mine optimisation. This paper further develops ideas presented by the author (McCarthy, 2010) about developing a rational basis for optimising the production rate that recognises, in particular, the relationship between mining rate and head grade.

\section{Orebody size and mining rate}

With the exception of flat tabular orebodies, as the orebody gets bigger:

- The available tonnes per vertical metre increases.

- For a pit, the stripping ratio to a particular depth decreases.

- For an underground mine, the development efficiency (tonnes per metre) increases.

- Possible stope sizes get bigger (to a geotechnical limit).

- Lower-cost and more productive mining methods become possible.

- The average capital investment per tonne of eventual production decreases.

- The physical limit to the mine production rate increases.

- The economically optimum mining rate increases.

However, increasing the production rate may have disadvantages:

- The required total capital investment increases.

- The required working capital, including pre-stripping or advance development, increases.

- Step capacity limits are reached, requiring further capital investment.

- Head grade to the mill decreases, for reasons discussed following.

- Control of the mining process begins to deteriorate after some point.

- The physical limit of production from the orebody is approached.

- Potentially negative social and environmental impacts increase.

- The rate of waste production and disposal increases.

\section{The process of optimisation}

Ideally, a feasibility study would result in an optimised design for the mine and processing plant. In reality, many studies are constrained by time, budget and data to achieve a minimum economic hurdle, without really determining how much better the project could be with further study. The gross variables under the designer's control are the cutoff grade, production rate, mining method and process design. Of these, the 
mining method and process design can be selected using well-established criteria based on experience, field data and test work.

The sensitivity of project value (however defined) to the key parameters of production rate and cutoff grade can be determined by varying those parameters in a model. For each combination, it is necessary to design and schedule the mine, estimate costs and evaluate the financial result. A discreet (although perhaps daunting) set of combinations is sufficient to estimate the shape of the entire value surface and to identify the optimum. Optimisation approaches may include linear programming, genetic algorithms and Monte Carlo simulation.

The objectives of optimisation must be aligned with the corporate objectives of the owner. Some stated corporate objectives, such as maximising annual ounces of gold production or maximising mine life, cannot be optimised. A large sub economic project will satisfy the former objective while a small sub economic project will satisfy the latter. For short-life projects, increasing the mining rate increases the risk that most of the production will be delivered into a trough in the product price. Sensitivity analysis based on a range of price scenarios will identify the rate that yields an acceptable risk.

There is also the problem of capital allocation between competing projects. If there is no restriction on the available capital then corporate value is maximised by maximising the Net Present Value (NPV) of every available viable project and carrying all of them through to production. In the real world, where available capital is restricted, the corporation must select projects for investment using some ranking technique. Economic theory says that projects should be ranked using the Present Value Ratio (PVR), which is the ratio of NPV to initial capital investment. For simplicity, the capital investment is usually taken to be the total of negative cash flows prior to achieving positive cash flows.

If the perceived risks are similar, projects with higher PVRs are selected before those with lower PVRs. A project with a high NPV but a low PVR may require more capital than the corporation (or the investment community) is able or willing to risk, or if developed it may displace alternatives which would have provided a better aggregate return on investment.

From the above, the mining rate should be optimised to maximise the project NPV at the corporation's agreed discount rate, provided that this leaves it with a PVR that will make it an attractive investment. Arguably, the mining rate should be changed (and possibly reduced) to improve the PVR, even at the expense of NPV, if this will allow the project to proceed in competition with others. This observation emphasises the importance of right-sizing the operation rather than pushing throughput into the limiting range.

\section{$4 \quad$ Head grade and mining rate}

The grade-tonnage curve is an essential tool in mine planning, allowing the designer to choose a small, high-grade option or a large, low-grade option, or any option in between these limits. For each option there is a set of corresponding cutoff grades used in planning and operations. Different mining and processing rates can be applied to each size option, each having a different NPV. Smith (1997) describes the NPV maximum value as a "failure point", noting that it is an upper economic limit for the possible range of production rates rather than an optimum rate. Smith's (1997) paper deals with economic criteria and not with the practical implications of high mining rates, which usually become important well before the NPV maximum value is reached.

The author has observed that mine head grade tends to fall as the mining rate increases in a way that cannot be accounted for by changes in the cutoff grade alone. This is well illustrated by Figure 1, which shows the history of production rate and head grade at the underground Henty Gold Mine now operated by Unity Mining Limited. Unusually, this mine went through a period of more than ten years in which the production rate steadily increased while the head grade fell. This raises the obvious question of whether the mining rate was increased to compensate for a falling head grade, or whether the falling head grade was a result of a reduced cutoff grade and increased mining dilution. Actually both effects occurred and 
cannot now be quantified, but the outcome can be seen in Figure 2 which plots the head grade as a function of mining rate, where head grade is expressed as a percentage of the weighted mean value and production rate as a percentage of the mean.

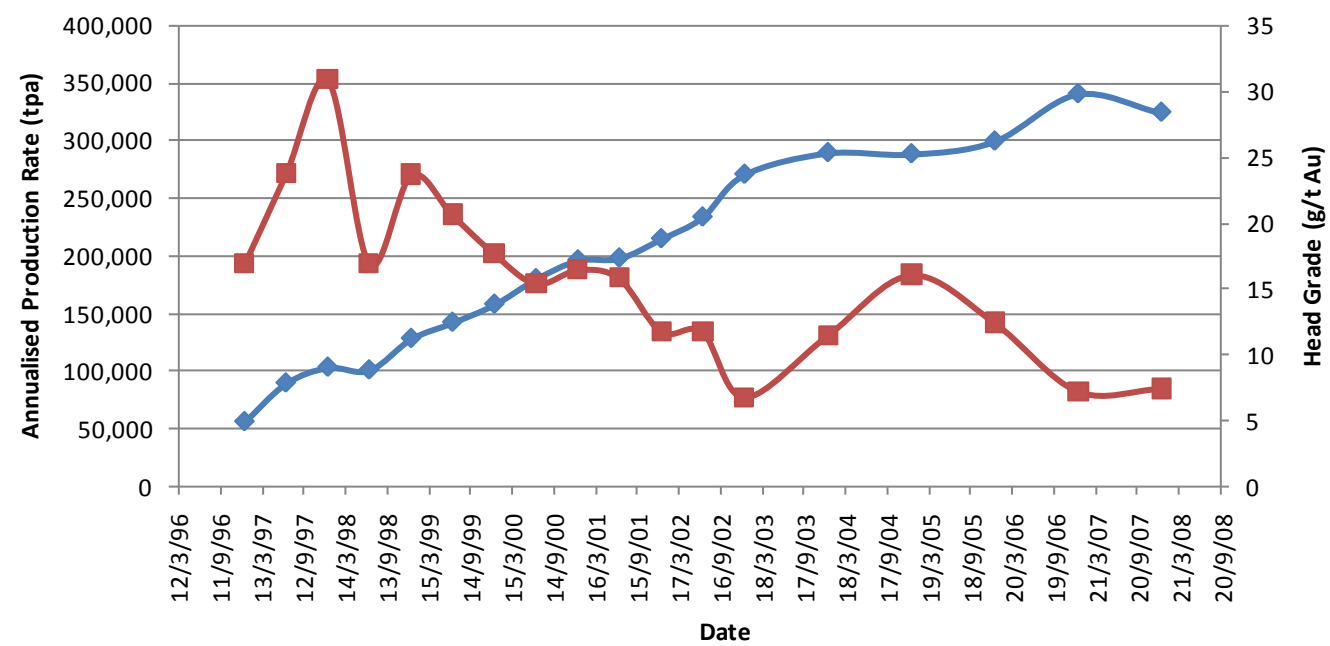

Figure 1 Production rate and head grade history at Henty Gold Mine, (head grade in red squares right axis, production rate in blue diamonds - left axis)

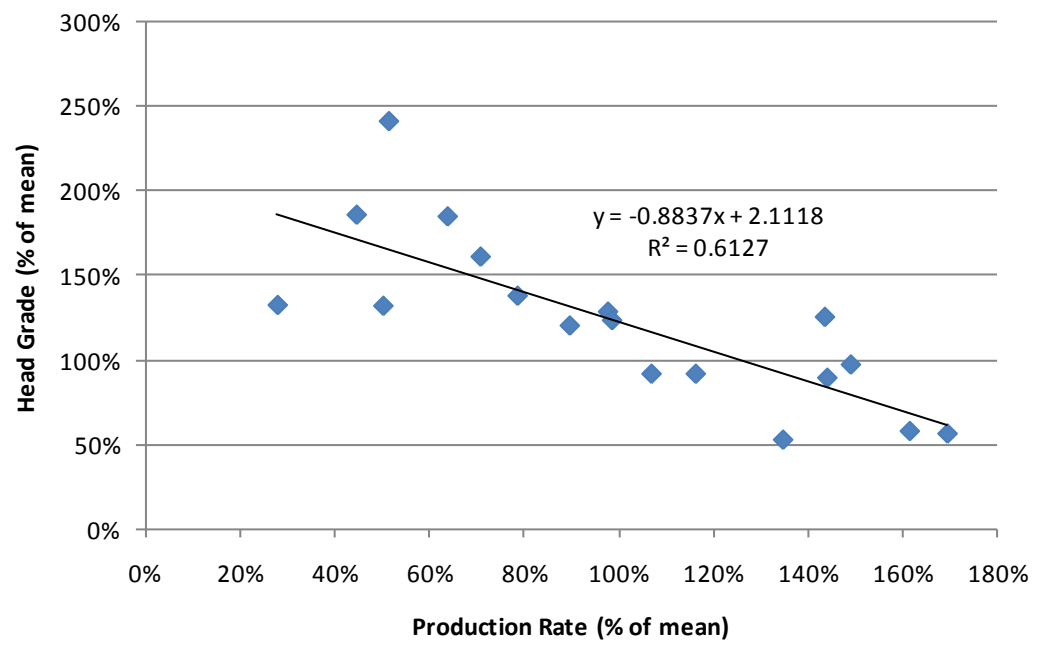

Figure 2 Head grade as a function of mining rate at Henty Gold Mine

Figure 2 shows that the head grade fell by about $0.9 \%$ for each $1 \%$ increase in production rate. Subject to orebody access it was open to the mine operators to choose an operating point along the best-fit line in Figure 2, which combines the influences of cutoff grade and dilution. The figure also suggests that selective mining is unlikely to increase the head grade to more than double its historical average value. This interpretation can be challenged on the basis that the decline in grade is the irreversible result of ore selection in an ageing mine. However, there are examples where the decreasing grade trend has been reversed by down-sizing the mining operation. Two examples are the Kambalda nickel mines, which substantially increased head grades at lower mining rates when sold off by WMC Ltd, and the CSA mine at Cobar, which substantially increased its head grade after 1997 by cutting its mining rate (Figure 3 ). 


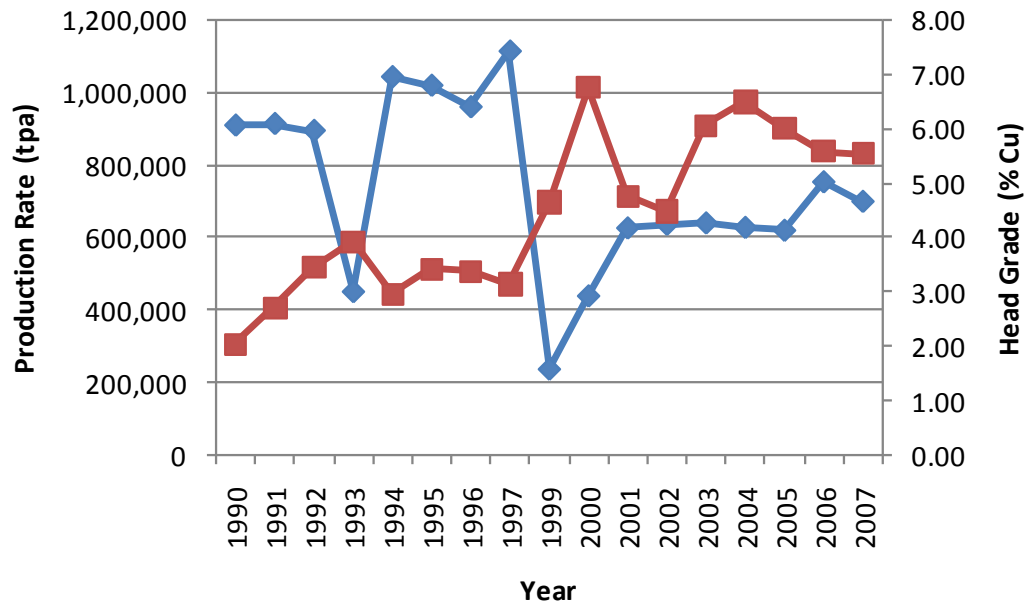

Figure 3 Production rate and head grade history at CSA Mine, (head grade in red squares - right axis, production rate in blue diamonds - left axis)

Examination of the production history of nearly every mine shows a strong relationship between mining rate and head grade. Larger scale mining is less selective, but the grade problem is as much due to human nature as it is to technology; if people are set unrealistic goals then "waste plus ore equals more ore". The author once reviewed a mine where the stope designs included discrete zones of hard, abrasive waste rock. Upon suggesting that a smaller, more selective stope design would be advantageous he was told, "We looked at that but we couldn't get the scheduled tonnes". The mill throughput was later reduced and the stopes redesigned, for a substantial improvement in mine NPV.

In general industry practice, the tonnage capacity of the process plant sets the rate. If the plant has been constructed with surplus capacity or expanded to that point then great pressure is put on the mine to fill the mill, often with scant regard for the effect on the quality of the material delivered.

\section{$5 \quad$ A simplified optimisation model}

If historical production data from a mine is analysed whereby:

- grade is expressed as a percentage of the weighted mean historical grade, and

- annual production is expressed as a percentage of the average annual historical production.

The linear best-fit line will have as its slope a dimensionless constant $k$ such that:

$$
k=-\Delta G(\%) / \Delta t(\%)
$$

where:

$\mathrm{G}=$ realised head grade (in \% metal).

$\mathrm{t}=$ the mining rate in tonnes per annum.

This is the value of $k=0.9$ that defines the slope of the line in Figure 2. Values of $k$ for selected Australian non-gold mines are given in Table 1 and for gold mines in Table 2. Note that the $\mathrm{R}^{2}$ value (or the Pearson Coefficient of Determination) is an indicator of how well the line fits the data. The closer the $R^{2}$ value is to 1 the better the fit. The non-gold results are based on historical production data compiled by Mudd (2009).

The derived $\mathrm{k}$ values for non-gold mines cluster around a mode of 0.3 and $70 \%$ of them lie between 0.2 and 0.5. These $\mathrm{k}$ values should be used with caution because they incorporate the influences of changes in cutoff grade, planned dilution, unplanned dilution and in some cases mining technology, as well as the effects of changes in orebody characteristics over time. Nevertheless, they reflect valid choices of operating points for these orebodies and it is better to use these values than to assume that the mining rate has no effect on head grade. 
Table 1 Values of $k$ for selected Australian metal mines, annual data

\begin{tabular}{|c|c|c|c|c|c|c|}
\hline Name & Period & Minerals & Method & k & $\mathbf{R}^{2}$ & Comment \\
\hline Osborne & 1997-2005 & $\mathrm{Cu} / \mathrm{Au}$ & UG & 2.10 & 0.536 & \\
\hline Mt Lyell & 1934-1974 & $\mathrm{Cu} / \mathrm{Ag} / \mathrm{Au}$ & Mainly OC & 1.21 & 0.358 & \\
\hline Peak & 1993-2008 & $\mathrm{Pb} / \mathrm{Ag} / \mathrm{Zn} / \mathrm{Cu} / \mathrm{Au}$ & UG & 1.12 & 0.610 & \\
\hline Mt Lyell & $1900-1933$ & $\mathrm{Cu} / \mathrm{Ag} / \mathrm{Au}$ & UG and $O C$ & 0.94 & 0.526 & Early years of mining \\
\hline Mount Morgan & 1933-1981 & $\mathrm{Cu} / \mathrm{Ag} / \mathrm{Au}$ & OC & 0.52 & 0.214 & \\
\hline Broken Hill & 1900-2008 & $\mathrm{Pb} / \mathrm{Ag} / \mathrm{Zn}$ & UG & 0.51 & 0.400 & $\begin{array}{l}\text { Multiple mines on } \\
\text { one orebody }\end{array}$ \\
\hline Argyle & 1979-2008 & Diamonds & $\mathrm{OC}$ & 0.48 & 0.192 & \\
\hline Rum Jungle & 1954-1970 & $\mathrm{U} / \mathrm{Cu}$ & OC & 0.48 & 0.342 & \\
\hline McArthur River & 1995-2008 & $\mathrm{Pb} / \mathrm{Ag} / \mathrm{Zn}$ & UG & 0.41 & 0.458 & \\
\hline Kambalda & 1967-2004 & $\mathrm{Ni}$ & UG & 0.36 & 0.597 & \\
\hline Century & 2000-2008 & $\mathrm{Pb} / \mathrm{Ag} / \mathrm{Zn}$ & OC & 0.35 & 0.563 & \\
\hline Mary Kathleen & 1959-1982 & $u$ & OC & 0.34 & 0.146 & \\
\hline CSA & 1968-2007 & $\mathrm{Pb} / \mathrm{Ag} / \mathrm{Zn} / \mathrm{Cu}$ & UG & 0.29 & 0.122 & \\
\hline Olympic Dam & 1988-2008 & $\mathrm{Cu} / \mathrm{U} / \mathrm{Ag} / \mathrm{Au}$ & UG & 0.28 & 0.811 & \\
\hline Cannington & 1997-2008 & $\mathrm{Pb} / \mathrm{Ag} / \mathrm{Zn}$ & UG & 0.28 & 0.648 & \\
\hline Rosebery & $1937-1980$ & $\mathrm{~Pb} / \mathrm{Ag} / \mathrm{Zn} / \mathrm{Cu} / \mathrm{Au}$ & UG & 0.28 & 0.705 & $\begin{array}{l}\text { Milled multiple } \\
\text { mines after } 1980\end{array}$ \\
\hline Ranger & 1982-2008 & U & $\mathrm{OC}$ & 0.27 & 0.611 & \\
\hline Woodcutters & 1986-1999 & $\mathrm{Pb} / \mathrm{Ag} / \mathrm{Zn}$ & Mainly UG & 0.26 & 0.218 & \\
\hline Mt Lyell & 1975-2008 & $\mathrm{Cu} / \mathrm{Ag} / \mathrm{Au}$ & UG & 0.21 & 0.170 & $\begin{array}{l}\text { Non-selective caving } \\
\text { since } 1995\end{array}$ \\
\hline Moonta & $1890-1923$ & $\mathrm{Cu}$ & UG and $O C$ & 0.21 & 0.162 & \\
\hline Woodlawn & 1979-1989 & $\mathrm{Pb} / \mathrm{Ag} / \mathrm{Zn} / \mathrm{Cu} / \mathrm{Au}$ & OC & 0.13 & 0.113 & \\
\hline Mt Isa Copper & 1943-2008 & $\mathrm{Cu}$ & UG & 0.11 & 0.151 & \\
\hline Mt Isa Lead & 1931-2005 & $\mathrm{Pb} / \mathrm{Ag} / \mathrm{Zn}$ & UG & 0.10 & 0.271 & \\
\hline
\end{tabular}

Table 2 Values of $k$ for selected Australian gold mines

\begin{tabular}{lcccccl}
\hline Name & Period & Minerals & Method & $\mathbf{k}$ & $\mathbf{R}^{\mathbf{2}}$ & Comment \\
\hline Beaconsfield & $1999-2010$ & Au & UG & 0.88 & 0.207 & Quarterly data \\
Henty & $1996-2007$ & Au & UG & 1.02 & 0.641 & Six monthly data \\
\hline
\end{tabular}

The two gold mine examples are from narrow-vein high-grade mines, suggesting that a value closer to $\mathrm{k}=1$ may apply. More research is required. The use of $k$ in optimisation is illustrated in the following two examples. 


\section{5. $1 \quad$ Example 1}

A mine is operating at a rate of $1 \mathrm{Mtpa}$ at a head grade of $2 \% \mathrm{Cu}$. An expansion to $1.5 \mathrm{Mtpa}$ is proposed and a value of $\mathrm{k}=0.3$ is inferred from similar deposits. The new head grade can be calculated from:

$$
\begin{gathered}
\mathrm{G}_{2}=\mathrm{G}_{1}\left(1-\mathrm{k}\left(\mathrm{t}_{2}-\mathrm{t}_{1}\right) / \mathrm{t}_{1}\right) \\
\mathrm{G}_{2}=2 \times(1-0.3 \times(1.5-1.0) / 1) \\
\mathrm{G}=1.7 \% \mathrm{Cu} .
\end{gathered}
$$

\section{2 Example 2}

A planned underground gold mine is based on an ore reserve of $18 \mathrm{Mt}$ at $5 \mathrm{~g} / \mathrm{t} \mathrm{Au}$. The orebody extends over 600 vertical metres. Adopting an equivalent vertical advance rate of $50 \mathrm{~m} /$ year gives a mine life of 12 years and a production rate of $1.5 \mathrm{Mtpa}$. It is assumed that the competent person preparing the ore reserve estimate allowed for dilution at a mining rate of $1.5 \mathrm{Mtpa}$. A value of $\mathrm{k}=0.5$ is inferred from similar deposits. Using the approach in Example 1, the following head grades can be predicted:

\begin{tabular}{cc}
\hline Rate (Mtpa) & Grade $(\mathrm{g} / \mathrm{t})$ \\
\hline 0.5 & 6.7 \\
1.0 & 5.8 \\
1.5 & 5.0 \\
2.0 & 4.2 \\
2.5 & 3.3 \\
\hline
\end{tabular}

This information can be used in financial modelling to further optimise the production rate.

\section{$6 \quad$ Estimating the value of $k$}

As a first approach to estimating the grade-rate relationship, it is possible to estimate the head grade that would result from applying the selected cutoff grade at specific mining rates as follows:

- Assuming that the exploration drilling is representative, at a mining rate of zero (i.e. with infinite selectivity) the head grade would be close to the average grade of the above-cutoff drill intercepts composited to minimum mining width. From this the intercept value on the grade axis can be derived.

- Using the most selective practical mining method the resulting head grade can be estimated from the dilution history of similar operations. Such selective methods might include the use of a $1.0 \mathrm{~m}$ wide bucket on a $60 \mathrm{t}$ excavator in an open pit, or hand-held cut and fill underground mining. In either case intensive grade control would be assumed and a vertical advance rate of around $30 \mathrm{~m}$ per year might be expected.

- Using a conventional approach to planning with a vertical advance rate of around $50 \mathrm{~m}$ per year, the head grade at the chosen cutoff grade can be estimated.

- An upper limiting case occurs in an open pit when the rate is limited by the highest benches and the largest equipment that can operate within the pit. In an underground mine, the limit might occur using sublevel open stoping with a highly regularised stope shape and unlimited advanced development. In either case a vertical advance rate approaching $100 \mathrm{~m}$ per year would apply. The geometric dilution would be substantial and grade control would be ineffective.

- A limiting value for $\mathrm{k}$ is set by assuming that the additional tonnage mined is all pure waste.

Using the above point estimates, a curve can be fitted to give a grade-tonnage relationship, or to estimate the value of $k$, for any selected cutoff grade. 
An example is provided by the history of one high-grade gold deposit. Highly selective mining in the 19th century gave a head grade of $90 \mathrm{~g} / \mathrm{t} \mathrm{Au}$, whereas modern hand-held cut and fill methods gave a head grade of $30 \mathrm{~g} / \mathrm{t} \mathrm{Au}$. This fell to 15-20 g/t Au using mechanised cut and fill and was estimated to have fallen further, to an estimated $10 \mathrm{~g} / \mathrm{t} \mathrm{Au}$, if sublevel benching had been attempted. The cutoff grade was about the same for each period; only the rate of mining changed, with an associated impact on dilution.

\section{Conclusion}

The mine production rate should be selected based on studies which will identify the maximum return on investment over a range of sensitivity scenarios. While unit (per tonne) capital and operating costs may be reduced as the mining rate is increased, other negative influences become important. The influence of the mining rate on head grade is a key consideration. Mine planning models should incorporate a mechanism for recognising the real-world relationship between mining rate and head grade.

\section{References}

Hoover, H.C. (1909) Principles of Mining, McGraw-Hill, New York, pp. 153-160.

McCarthy, P.L. (1993) Economics of Narrow Vein Mining, in Seminar Narrow Vein Mining, Australasian Institute of Mining and Metallurgy, 17-18 June, Bendigo, Australia, pp. 89-97.

McCarthy, P.L. (2010) Setting Plant Capacity, Metallurgical Plant Design and Operating Strategies, Transactions of the Institution of Mining and Metallurgy - Section C, Vol. 119, No. 4, pp. 184-190.

Mudd, G.M. (2009) The Sustainability of Mining in Australia: Key Production Trends and Their Environmental Implications for the Future, Research Report No RR5, Department of Civil Engineering, Monash University and Mineral Policy Institute, Revised April 2009.

Smith, L.D. (1997) A Critical Examination of the Methods and Factors Affecting the Selection of an Optimum Production Rate, CIM Magazine, Bulletin Vol. 90, No. 1007, February 1997.

Tatman, C.R. (2001) Production Rate Selection for Steeply Dipping Tabular Deposits, Mining Engineering, October 2001, pp. 62-64. 